\title{
Pengaruh Perendaman Kopi Robusta dan Arabika terhadap Kekerasan Resin Komposit Nanofiller
}

\author{
Fransiska M. Pardosi,,${ }^{1 *}$ Darmawati A. Indraswari, ${ }^{2}$ Lusiana Batubara, ${ }^{2}$ Nadia \\ Hardini ${ }^{*}$
}

\author{
${ }^{1}$ Departemen Kedokteran Gigi Fakultas Kedokteran Universitas Diponegoro, Semarang, \\ Indonesia \\ ${ }^{2}$ Departemen Kedokteran Universitas Diponegoro, Semarang, Indonesia \\ *Kedua Penulis memiliki kontribusi yang sama dalam penulisan naskah. \\ *Email korespondensi: hardininadia@gmail.com
}

\begin{abstract}
Nanofiller composite resin has small filler size which enhances its properties. However, these properties could decrease due to several factors. Acidic liquid such as coffee could reduce the hardness of composite resin. This study was aimed to analyze the effect of robusta and arabica coffee immersion on the hardness of nanofiller composite resin. A total of 27 composite resin samples were used and then were polished by using a soflex disc for 30 seconds on each roughness level. Samples were then divided into three groups, as follows: the control group with artificial saliva and the treatment groups with robusta coffee and arabica coffee. The composite resin molds were immersed in the three groups for 5 days. After five days of immersion, the hardness of the sample was tested by using a Vickers hardness tester. Artificial saliva as the control group had the highest mean hardness value of $112.98 \pm 8.67 \mathrm{VHN}$, followed by robusta coffee, and then by arabica coffee. The One Way Anova and post hoc LSD test showed that there were significant differences in all groups $(\mathrm{p}<0.05)$ except for the two treatment groups, namely robusta and arabica coffee groups which did not show any significant difference in the resin hardness ( $p>0.05)$. In conclusion, robusta and arabica coffee affect the hardness of the nanofiller composite resin, but there is no significant difference in the hardness between the robusta and arabica coffee groups.

Keywords: composite resin hardness, nanofiller, robusta coffee, arabica coffee
\end{abstract}

\begin{abstract}
Abstrak: Resin komposit nanofiller memiliki ukuran filler kecil yang dapat meningkatkan fungsinya namun fungsi tersebut dapat menurun oleh beberapa hal. Cairan asam yang dikonsumsi seperti kopi dapat menurunkan kekerasan resin komposit. Penelitian ini bertujuan untuk mengetahui pengaruh perendaman kopi robusta dan arabika terhadap kekerasan resin komposit nanofiller. Sampel resin komposit yang digunakan sebanyak 27 buah dan dilanjutkan dengan pemolesan menggunakan soflex disc selama 30 detik setiap tingkat kekasarannya. Sampel kemudian dibagi dalam tiga kelompok, yaitu kelompok kontrol dengan saliva buatan dan dua kelompok perlakuan dengan kopi robusta dan arabika. Sebanyak 27 buah resin komposit direndam ke dalam tiga kelompok tersebut selama lima hari kemudian diuji kekerasannya dengan vickers hardness tester. Saliva buatan sebagai kelompok kontrol memiliki nilai rerata kekerasan tertinggi sebesar 112,98 $\pm 8,67 \mathrm{VHN}$, diikuti kopi robusta, dan nilai terendah yaitu kopi arabika. Hasil uji One Way Anova dan post hoc LSD menunjukkan terdapat perbedaan bermakna pada semua kelompok $(\mathrm{p}<0,05)$ kecuali pada kedua kelompok perlakuan yaitu antara kopi robusta dan arabika tidak menunjukkan adanya perbedaan kekerasan yang bermakna $(p>0,05)$. Simpulan penelitian ini ialah kopi robusta dan arabika memengaruhi kekerasan resin komposit nanofiller namun tidak terdapat perbedaan kekerasan antara keduanya.
\end{abstract}

Kata kunci: kekerasan resin komposit, nanofiller, kopi robusta, kopi arabika 


\section{PENDAHULUAN}

Indonesia memiliki permasalahan kesehatan gigi dan mulut yang cukup tinggi yaitu sebanyak 57,6\% menurut data RISKESDAS tahun 2018. Salah satu penyakitnya ialah karies dengan prevalensi yang tinggi yaitu $88,8 \% .{ }^{1}$ Karies merupakan kerusakan dari jaringan keras gigi yang rentan karena adanya produk asam dari hasil fermentasi karbohidrat yang dilakukan oleh bakteri. ${ }^{2}$ Perawatan gigi pada penyakit ini perlu dilakukan untuk mencegah kerusakan yang lebih lanjut, salah satu perawatan dalam penanganan karies yaitu resin komposit. ${ }^{2,3}$

Resin komposit adalah bahan material restorasi langsung yang digunakan untuk mengganti jaringan gigi yang hilang, dan memperkuat mahkota, lapisan serta jaringan gigi lainnya. ${ }^{4}$ Salah satu keuntungan dari resin komposit yaitu mengikuti bentuk alami gigi, sehingga resin komposit lebih disukai sebagai bahan tumpatan. ${ }^{5-7}$ Resin komposit telah mengalami banyak perkembangan untuk meningkatkan sifatnya, salah satunya resin komposit nanofiller dengan tambahan teknologi nano dalam bahan pengisi komposit yang memiliki filler yang lebih kecil sebagai alternatif untuk mengatasi kekurangan yang dimiliki oleh jenis komposit lain. ${ }^{5,7-9}$ Resin ini memberikan pengerutan yang lebih rendah. ${ }^{4,10-12}$ Selain itu, resin ini dapat membentuk kontur yang baik dan digunakan sebagai restorasi pada gigi anterior maupun posterior, terlebih karies yang sering terjadi pada gigi posterior karena bentuk pit dan fissure yang dalam mengakibatkan makanan sering menumpuk. ${ }^{13,14}$ Resin komposit memiliki beberapa sifat, salah satunya ialah kekerasan. ${ }^{4}$ Kekerasan resin komposit berperan sebagai alat ukur untuk mengetahui ketahanan permukaan terhadap tekanan pengunyahan. ${ }^{10,14}$ Penurunan kekerasan dapat terjadi bila terpapar cairan asam dalam jangka waktu yang lama. ${ }^{4,7,10}$ Cairan tersebut dapat menyebabkan pemisahan matriks atau degradasi hidrolitik partikel yang dapat memengaruhi sifat resin komposit seperti kekerasan. ${ }^{10,15}$ Sebagai salah satu contoh minuman yang mengandung asam yaitu kopi.

Kopi telah menjadi suatu gaya hidup masyakarat pada era modern sekarang ini. ${ }^{16,17}$ Berdasarkan Pusat Data dan Sistem Informasi Pertanian Kementerian Pertanian, konsumsi kopi Indonesia sepanjang periode 2016-2021 diprediksi tumbuh dengan rerata 8,22\%/tahun. ${ }^{18}$ Frekuensi minum kopi dan jumlah kopi dikonsumsi per hari rata-rata sebanyak 2-4 cangkir/hari. ${ }^{19}$ Rentang usia terbanyak untuk peminum kopi pada usia dewasa muda sekitar 20-34 tahun. ${ }^{19,20}$ Pada usia peminum kopi ini juga terdapat prevalensi karies yang cukup tinggi. ${ }^{1}$

Terdapat dua jenis kopi yang paling banyak dibudidayakan di Indonesia, yaitu kopi robusta dan arabika. ${ }^{17,21-23}$ Telah diketahui bahwa kandungan asam pada kopi seperti asam klorogenat dapat menurunkan sifat mekanik resin komposit. ${ }^{7,24,25}$ Kandungan asam pada kopi dapat menyebabkan perubahan struktur resin komposit dengan pembentukan pori pada permukaan yang berakibat putusnya ion gugus metakrilat dengan ikatan antara filler dan coupling agent, sehingga ikatan tersebut terlepas dan menyebabkan degradasi matriks. Degradasi matriks ini akan menyebabkan menurunnya sifat resin komposit, salah satunya ialah kekerasannya. ${ }^{8-10}$

Penelitian sebelumnya menggunakan larutan kopi robusta terhadap kekuatan tekan resin komposit nanofiller melaporkan adanya penurunan kekuatan, ${ }^{26}$ namun penelitian dengan dua jenis kopi yang juga memiliki kandungan asam dan $\mathrm{pH}$ rendah terhadap kekerasan resin komposit nanofiller belum pernah dilaporkan. Berdasarkan latar belakang tersebut, maka penulis terdorong untuk meneliti apakah terdapat perbedaan pengaruh di antara kedua jenis kopi yaitu kopi robusta dan arabika terhadap kekerasan resin komposit nanofiller.

\section{METODE PENELITIAN}

Penelitian ini merupakan penelitian true experimental dengan posttest-only control group design. Sampel penelitian ini menggunakan resin komposit nanofiller Z350 XT Z350XT 3M shade A3. Pembuatan sampel menggunakan cetakan akrilik berbentuk lingkaran dengan diameter 10 $\mathrm{mm}$ dan ketebalan $2 \mathrm{~mm}$ sebanyak 30 buah 
yang didapatkan dari rumus Federer dan drop out sebesar $10 \%$, sehingga besar sampel yang digunakan sebanyak 27 buah. Sampel kemudian disinar menggunakan light curing unit (LCU) selama 20 detik dengan jarak penyinaran $1 \mathrm{~mm}$. Seluruh sampel dibagi secara acak dengan metode simple random sampling menjadi tiga kelompok, yaitu satu kelompok kontrol yang direndam dengan saliva buatan $\mathrm{pH} 7$ dan dua kelompok perlakuan menggunakan kopi robusta dan arabika yang ditambahkan saliva buatan dengan masing-masing sampel sebanyak 9 buah. Perendaman ini dilakukan selama 5 hari dengan pergantian larutan yang lama dengan yang baru setiap harinya. Sebelum dilakukan perlakuan, sampel disimpan dalam inkubator selama 24 jam dengan suhu $37^{\circ} \mathrm{C}$ menggunakan akuades steril. Sampel yang telah diinkubasi kemudian direndam pada kelompok kontrol dan perlakuan masing-masing sebanyak 5 ml. Setelah lima hari perendaman, sampel diuji kekerasannya menggunakan alat Micro Vickers Hardness Tester yang diberi beban 100 gr selama 15 detik pada tiga titik permukaan sampel.

Jenis kopi yang digunakan dalam penelitian ini ialah kopi robusta dan arabika dengan tingkat sangrai dan kekasaran medium. Bubuk kopi tersebut diseduh menggunakan rasio 1:10 yaitu 10 gr bubuk kopi dengan $100 \mathrm{ml}$ air panas $100^{\circ} \mathrm{C}$. Kemudian, dilakukan pengukuran $\mathrm{pH}$ dan kadar asam klorogenat melalui uji kadar tanin pada larutan tersebut.

Data penelitian ini dianalisis menggunakan uji normalitas Shapiro Wilk dan homogenitas data dengan uji Levene. Selanjutnya dilakukan uji parametrik One Way Anova dan Post Hoc LSD untuk melihat perbedaan kekerasan masing-masing kelompok dengan signifikansi $\mathrm{p}<0,05$.

\section{HASIL PENELITIAN}

Kopi robusta memiliki pH sebesar 5,1 dan kopi arabika tidak berbeda jauh yaitu 4,7. Hasil tersebut juga serupa dengan kadar tanin yang tidak menunjukkan perbedaan yang jauh antara kopi robusta dan arabika, yaitu kopi robusta memiliki kadar sebesar
$1,094 \%$ sedangkan pada kopi arabika sebesar $1,027 \%$.

Tabel 1 memperlihatkan nilai rerata, simpangan baku, dan normalitas data kekerasan resin komposit nanofiller pada kelompok kontrol dan perlakuan. Terdapat perubahan kekerasan komposit pada kelompok kopi robusta dan arabika. Hal ini dapat diketahui dengan melihat nilai rerata kelompok saliva sebagai kelompok kontrol dimana kelompok saliva memiliki nilai yang lebih tinggi dibandingkan kelompok lainnya. Resin komposit nanofiller yang direndam dengan kopi arabika memiliki nilai rerata yang lebih rendah. Interpretasi nilai kekerasan yang rendah mengindikasikan bahwa sampel lebih lunak. Hasil data tersebut kemudian dilakukan analisis distribusi data dengan Shapiro Wilk. Kelompok saliva buatan, kopi robusta, dan arabika menunjukkan nilai $\mathrm{p}>0,05$ yang menunjukkan data terdistribusi normal. Setelah itu, dilakukan uji homogenitas dengan uji Levene dan didapatkan nilai $\mathrm{p}>0,05$ yang menunjukkan data homogen.

Data penelitian ini terdistribusi normal dan homogen; oleh karena itu dilakukan uji parametrik dengan One Way Anova. Tabel 2 menunjukkan adanya perbedaan bermakna dengan nilai $\mathrm{p}<0,05$, dilanjutkan dengan uji post hoc LSD untuk mengetahui perbedaan kemaknaan pada masing masing kelompok.

Tabel 3 menunjukkan adanya perbedaan bermakna pada semua kelompok kecuali pada kelompok kopi robusta dengan arabika yang mendapatkan nilai $\mathrm{p}=0,567$ yang berarti tidak terdapat perbedaan bermakna antara keduanya.

\section{BAHASAN}

Penelitian ini bertujuan untuk mengetahui adanya pengaruh perendaman kopi robusta dan arabika terhadap kekerasan resin komposit nanofiller. Kopi memiliki kandungan asam dan $\mathrm{pH}$ rendah sehingga dapat memengaruhi kekerasan resin komposit. ${ }^{10,11} \mathrm{Hal}$ ini disebabkan adanya degradasi matriks yang terjadi akibat proses difusi air masuk ke dalam resin komposit yang berakibat lanjut berupa perubahan struktur mikro komposit. 
Tabel 1. Nilai rerata dan simpangan baku

\begin{tabular}{lccccc}
\hline Kelompok & N & $\begin{array}{c}\text { Mean } \pm \text { SD } \\
(\mathbf{V H N})\end{array}$ & $\begin{array}{c}\text { Min } \\
(\mathbf{V H N})\end{array}$ & $\begin{array}{c}\text { Max } \\
(\mathbf{V H N})\end{array}$ & Nilai p* $^{*}$ \\
\hline Saliva (Kontrol) & 9 & $112,98 \pm 8,67$ & 98,5 & 121,2 & 0,059 \\
Kopi Robusta & 9 & $93,22 \pm 7,40$ & 84,9 & 106,8 & 0,128 \\
Kopi Arabika & 9 & $91,21 \pm 5,61$ & 84,4 & 101,4 & 0,645 \\
\hline
\end{tabular}

*Uji normalitas Shapiro-Wilk, signifikansi $p>0,05$

Tabel 2. Uji parametrik One Way Anova

\begin{tabular}{lccc}
\hline & Kelompok & Mean \pm SD & Nilai $\boldsymbol{p}$ \\
\hline \multirow{3}{*}{ Kekerasan } & Saliva & $112,98 \pm 8,67$ & \\
& Kopi Robusta & $93,22 \pm 7,40$ & $<0,001^{*}$ \\
& Kopi Arabika & $91,21 \pm 5,61$ & \\
\hline
\end{tabular}

*Uji One Way Anova, signifikansi p<0,05

Tabel 3. Uji post hoc LSD

\begin{tabular}{lccc}
\hline Saliva - Kopi Robusta & $\begin{array}{c}\text { Kelompok Sampel } \\
\text { Saliva }- \text { Kopi Arabika }\end{array}$ & $\begin{array}{c}\text { Kopi Robusta }- \text { Kopi } \\
\text { Arabika }\end{array}$ \\
\hline Nilai p & $0,000^{*}$ & $0,000^{*}$ & 0,567 \\
\hline
\end{tabular}

*Uji post hoc LSD, signifikansi $\mathrm{p}<0,05$

Perubahan tersebut mengakibatkan terbentuknya pori pada resin komposit yang mengakibatkan penurunan kekerasan resin komposit. ${ }^{10,11,24}$ Selain itu, asam klorogenat mengandung senyawa fenol yang bila berkontak dengan resin komposit akan menunjukkan peningkatan penyerapan air dan kerusakan kimiawi pada permukaannya, sehingga berdampak pada sifat resin komposit. ${ }^{27}$ Penelitian ini selaras dengan penelitian Sari et $\mathrm{al}^{26}$ yang menunjukkan bahwa kandungan kimia yang terdapat pada kopi robusta yaitu asam klorogenat serta $\mathrm{pH}$ yang rendah dapat menurunkan kekuatan tekan resin komposit nanofiller. Tuncer et $\mathrm{al}^{28}$ menyatakan bahwa pada minuman yang memiliki $\mathrm{pH}$ rendah, resin komposit menunjukkan penyerapan dan kelarutan yang tinggi sehingga menyebabkan erosi yang akan memengaruhi keausan dan kekerasan permukaan resin komposit. Selain adanya degradasi matriks, penurunan kekerasan dapat terjadi karena adanya ikatan siloksan $\mathrm{Si}-\mathrm{O}-\mathrm{Si}$ yang terputus. Ikatan tersebut terbentuk antara filler dan coupling agent.
Degradasi pada ikatan siloksan ini menyebabkan filler terlepas dan terjadi penurunan kekerasan. $^{8}$

Pada penelitian ini digunakan resin komposit nanofiller Filtex $^{\mathrm{TM}}$ Z350 XT dengan monomer matriks resin bersifat hidrofilik, sehingga nilai penyerapan dan kelarutan air yang tinggi memudahkan putusnya ikatan antara siloksan dan filler. ${ }^{4,10}$ Filler yang terdapat pada resin ini merupakan kombinasi dari filler non aggregated silica dan zirconia di mana filler zirconia memiliki permukaan yang pori sehingga memudahkan proses terserapnya air dan terjadi penurunan resin komposit. ${ }^{29}$

Hasil penelitian ini menunjukkan bahwa terdapat perbedaan kekerasan resin komposit nanofiller antar kelompok, dan uji post hoc LSD menunjukkan adanya perbedaan bermakna pada semua kelompok kecuali pada kelompok perendaman kopi robusta dan arabika yang tidak memiliki perbedaan bermakna. Hal ini disebabkan karena $\mathrm{pH}$ antara kedua jenis kopi tersebut tidak berbeda jauh. Tingkat $\mathrm{pH}$ pada kopi 
robusta sebesar 5,1 dan kopi arabika sebesar 4,7. Perbedaan kekerasan yang tidak bermakna ini juga dipengaruhi oleh adanya kadar asam klorogenat pada kopi yang mengandung senyawa polifenol di mana pada penelitian ini kopi robusta sebesar $1,094 \%$ dan arabika $1,027 \%$. Senyawa polifenol yang berkontak dengan resin komposit akan merusak permukaan resin yang menyebabkan bahan restorasi menjadi lunak. ${ }^{27}$ Dengan kadar asam dan $\mathrm{pH}$ yang tidak berbeda jauh belum dapat melihat adanya perbedaan kekerasaan antara dua jenis kopi tersebut. Hasil penelitian ini pun selaras dengan penelitian Awliya et $\mathrm{al}^{30}$ yang melaporkan bahwa tidak terdapat perbedaan kekerasan yang bermakna setelah perendaman dengan empat jenis kopi yang berbeda yaitu American, Turkish, arabika, dan Espresso. ${ }^{30}$ Namun dari data penelitian ini, rerata kekerasan menunjukkan kelompok perlakuan dengan perendaman kopi arabika menurunkan kekerasan yang lebih besar daripada kopi robusta. Hal ini disebabkan karena $\mathrm{pH}$ dari kopi arabika lebih rendah daripada kopi robusta. Semakin rendah nilai $\mathrm{pH}$ maka semakin tinggi proses penyerapan air sehingga matriks resin komposit terputus dan dapat menurunkan kekerasan resin komposit.

\section{SIMPULAN}

Terdapat pengaruh perendaman kopi robusta dan arabika terhadap kekerasan resin komposit nanofiller, namun tidak terdapat perbedaan kekerasan resin komposit nanofiller yang bermakna antara kedua jenis kopi.

\section{Konflik Kepentingan}

Penulis menyatakan tidak ada konflik kepentingan dalam penelitian ini.

\section{DAFTAR PUSTAKA}

1. Badan Penelitian dan Pengembangan. Laporan Hasil Riset Kesehatan Dasar (Riskesdas) Indonesia tahun 2018. Riset Kesehatan Dasar 2018. Jakarta: Lemba-ga Penerbit Badan Penelitian dan Pengembangan Kesehatan, 2019; p. 204.

2. Yadav K, Prakash S. A review of dental caries.
Asian J Biomed Pharm Sci. 2016; 6(53):73-80.

3. Pitts NB, Zero DT, Marsh PD, Ekstrand K, Weintraub JA, Ramos-Gomez F, et al. Dental caries. Nat Rev Dis Prim. 2017; 25(3):17030.

4. Anusavice KJ, Shen C, Rawls HR. Philip's Science of Dental Material. Elsevier Health Science, 2014.

5. Sakaguchi RL, Powers JM. Craig's Restorative Dental Materials (13th ed). United States: Elsevier, 2012.

6. Moon J-D, Seon E-M, Son S-A, Jung K-H, Kwon Y-H, Park J-K. Effect of immersion into solutions at various $\mathrm{pH}$ on the color stability of composite resins with different shades. Restor Dent Endod. 2015;40(4):270.

7. da Silva TM, Dantas DCB, Franco TT, Franco LT, Huhtala MFRL. Surface degradation of composite resins under staining and brushing challenges. J Dent Sci. 2019;14(1):87-92.

8. Handayani DP, Puspitasari D, Dewi N. Efek perendaman rebusan daun sirih merah (Piper crocatum) terhadap kekerasan permukaan resin komposit. Maj Kedokt Gigi Indones. 2016;2(2):60.

9. Puspitasari SA, Siswomiharjdo W, Harsini H. Perbandingan kekasaran permukaan resin komposit nanofiller pada perendaman saliva $\mathrm{pH}$ asam. J Mater Kedokt Gigi. 2016;5(2):15.

10. Kafalia RF, Firdausy MD, Nurhapsari A. Pengaruh jus jeruk dan minuman berkarbonasi terhadap kekerasan permukaan resin komposit. Odonto Dental Journal. 2017;4(1):38-43.

11. Khan AA, Siddiqui AZ, Mohsin SF, AlKheraif AA. Influence of mouth rinses on the surface hardness of dental resin nano-composite. Pakistan J Med Sci. 2015;31(6):1485-9.

12. Devnani GL, Sinha S. Effect of nanofillers on the properties of natural fiber reinforced polymer composites. Mater Today Proc [Internet]. 2019;18(3):647-54.

13. Listrianah L, Zainur RA, Hisata LS. Gambaran karies gigi molar pertama permanen pada siswa-siswi Sekolah Dasar Negeri 13 Palembang Tahun 2018. JPP (Jurnal Kesehat Poltekkes Palembang). 2019; 13(2):136-49.

14. Basri MHC, Erlita I, Nahzi MYI. Kekasaran permukaan resin komposit nanofiller 
setelah perendaman dalam air sungai dan air PDAM. Dentino. 2017;II(1): 101-6.

15. Svizero N da R, de Góes ARCG, Bueno T de L, Di Hipólito V, Wang L, D’alpino PHP. Micro-sized erosions in a nanofilled composite after repeated acidic beverage exposures: consequences of clusters dislodgments. J Appl Oral Sci. 2014;22(5):373-81.

16. Chismirina S, Andayani R, Ginting R. Pengaruh kopi arabika (Coffea arabica) dan kopi robusta (Coffea canephora) terhadap viskositas saliva secara in vitro. Cakradonya Dent J. 2014;6(2):687-91.

17. Farhaty N, Muchtaridi. Tinjauan kimia dan aspek farmakologi senyawa asam klorogenat pada biji kopi: Review. Farmaka Suplemen. 2014;14(1):214-27.

18. Kementerian Pertanian. Outlook Kopi Komoditas Pertanian Subsektor Perkebunan. Pus Data Dan Sist Inf Pertan Sekr Jenderal. 2016;116.

19. Amaluddin NA, Malik UK. Pengaruh konsumsi kopi terhadap peningkatan tekanan darah. Magna Medika. 2018; 1(5):44-9.

20. Drewnowski A, Rehm CD. Sources of caffeine in diets of US children and adults: Trends by beverage type and purchase location. Nutrients. 2016;8(3):154.

21. Tripetch P, Borompichaichartkul C. Effect of packaging materials and storage time on changes of colour, phenolic content, chlorogenic acid and antioxidant activity in arabica green coffee beans (Coffea arabica L. cv. Catimor). J Stored Prod Res. 2019;84:101510.

22. Aditya I, Nocianitri K, Yusasrini N. Kajian kandungan kafein kopi bubuk, nilai $\mathrm{pH}$ dan karakteristik aroma dan rasa seduhan kopi jantan (pea berry coffee) dan betina (flat beans coffee) jenis arabika dan robusta. J Ilmu dan Teknol
Pangan. 2016;5(1):1-12.

23. Dias R, Benassi M. Discrimination between arabica and robusta coffees using hydrosoluble compounds: is the efficiency of the parameters dependent on the roast degree? Beverages. 2015;1(3): 127-39.

24. Sitanggang P, Tambunan E, Wuisan J. Uji kekerasan komposit terhadap rendaman buah jeruk nipis (Citrus Aurantifolia). eGigi. 2015;3(1):229-34.

25. Alshabib A, Silikas N, Watts DC. Hardness and fracture toughness of resincomposite materials with and without fibers. Dent Mater. 2019;35(8):1194203.

26. Andari ES, Wulandari E, Robin DMC. Efek larutan kopi robusta terhadap kekuatan tekan resin komposit nanofiller (The effect of robusta coffee solution to nanofilled composite resin compressive strength). Stomatognatic (JKG Unej). 2014;11(1):6-11.

27. Rindy SD. Pengaruh perendaman lempeng akrilik serat kaca 3\% (heat cured) dalam larutan kopi robusta terhadap kekuatan impak [Tesis]. Malang: Universitas Brawijaya; 2013.

28. Tuncer D, Karaman E, Firat E. Does the temperature of beverages affect the surface roughness, hardness, and color stability of a composite resin? Eur J Dent. 2013;7(2):165-71.

29. Rahim TNAT, Mohamad D, Md Akil H, Ab Rahman I. Water sorption characteristics of restorative dental composites immersed in acidic drinks. Dent Mater. 2012;28(6):63-70.

30. Awliya WY, Al-Alwani DJ, Gashmer ES, AlMandil HB. The effect of commonly used types of coffee on surface microhardness and color stability of resinbased composite restorations. Saudi Dent J. 2010;22(4):177-81. 